\title{
Correction to: Differential diagnosis of sinonasal extranodal NK/T cell lymphoma and diffuse large B cell lymphoma on MRI
}

\section{Yun Chen ${ }^{1,2} \cdot$ Xinyan Wang ${ }^{1} \cdot$ Long $\mathrm{Li}^{3} \cdot$ Wei $\mathrm{Li}^{1} \cdot$ Junfang Xian ${ }^{1}$}

Published online: 2 July 2020

(C) Springer-Verlag GmbH Germany, part of Springer Nature 2020

Correction to: Neuroradiology (2020) https://doi.org/10.1007/s00234-020-02471-3

The above article was published online with incorrect Fig. 1. The correct Fig. 1 is presented below.

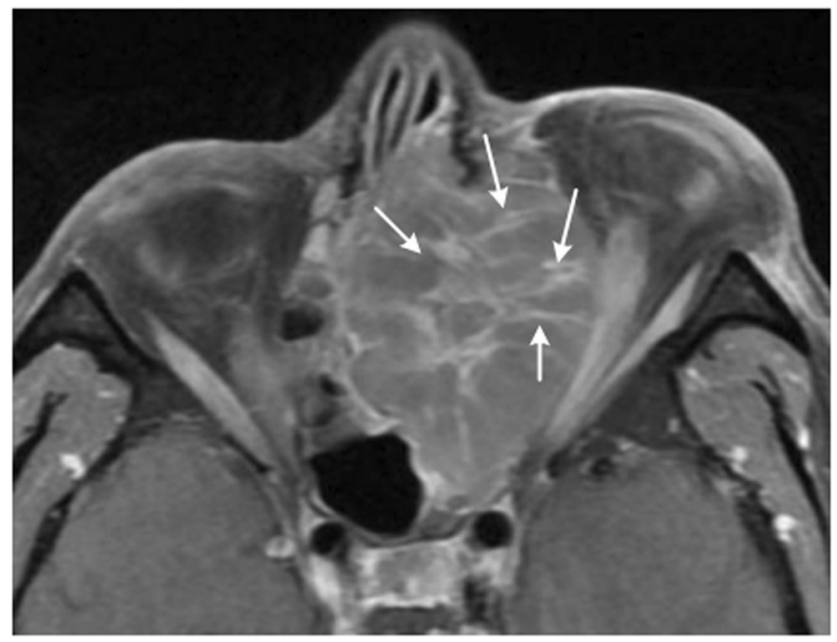

Fig. 1 An example for the septal enhancement pattern. Axial delayed contrast T1WI shows marked enhanced striations (arrows) within mild enhanced solid components of the tumor
Publisher's note Springer Nature remains neutral with regard to jurisdictional claims in published maps and institutional affiliations.

The online version of the original article can be found at https://doi.org/ $10.1007 / \mathrm{s} 00234-020-02471-3$

Junfang Xian

cjr.xianjunfang@vip.163.com

1 Department of Radiology, Beijing Tongren Hospital, Capital Medical University, Beijing 100730, China

2 Department of Radiology, Third Affiliated Hospital of Soochow University, Changzhou, Jiangsu, China

3 Department of Radiology, Xianghe People's Hospital, Langfang, Hebei, China 